\title{
AVALIAÇÃO DE ASSENTAMENTOS E HABITAÇÕES PERMANENTES CONSTRUÍDOS PÓS-DESASTRES DE 2008 NO VALE DO ITAJAÍ, SC
}

\author{
Alberto Lohmann, Doutor (UDESC) \\ Fernando Barth, Doutor (UFSC)
}

O efeito devastador dos desastres naturais exige medidas emergenciais de atendimento à população, tais como socorro, assistência médica, social e econômica, assim como o provimento de abrigos e habitações, necessários para que possa ser realizada a reconstituição de infraestruturas e do ambiente construído. A disponibilização de construções rápidas e que não tenham o caráter provisório é de extrema importância para o restabelecimento das famílias. Sendo que para isso, deve-se levar em consideração às necessidades da população, conforme a região e situação de desastre.

Neste contexto, a pesquisa trata das habitações de caráter permanente construídas pós-desastres naturais ocorridos em 2008 no Vale do Itajaí, em Santa Catarina, com 1,5 milhões de pessoas afetadas, em 77 municípios e um total de 5.737 desabrigados. Avaliou-se o desempenho a partir dos requisitos e critérios estabelecidos pela NBR 15.575 para edificações habitacionais, em três esferas, desempenho térmico, funcional e adequação ambiental. Essa abordagem buscou contribuir para um registro das soluções, mediante a elaboração de um banco de dados, que determina as melhores às respostas arquitetônicas frente aos desastres, identificando, também, os problemas para uma possível reformulação para o futuro provimento de habitações para a população atingida por desastres.

Segundo Davis (1980), os desastres são uma relação entre algum tipo de risco, com uma condição perigosa que aumenta a vulnerabilidade do sistema - como por exemplo o modelo de ocupação urbana, onde os pobres ocupam as piores terras e as partes mais densas e perigosas das cidades. Para Davidson et all (2006), a multiplicidade de escoIhas oferecidas à população, a responsabilidade dos usuários pelas decisões feitas e a articulação de recursos locais e externos por intermédio de uma organização local são estratégias interessantes para o provimento de habitações.

Foram avaliados cinco assentamentos, nas cidades que declararam Estado de Calamidade Pública - Brusque,
Camboriú, Gaspar, Pomerode e Rodeio - mostrando que há diferença na locação das unidades quanto ao seu número (7 a 71 lotes) e sua forma (linear e radial). Somente no município de Camboriú o assentamento avaliado foi inserido no tecido urbano existente. Quanto as unidade de habitação: os acessos principais e secundários configuram a circulação no interior da edificação; os requisitos normativos de funcionalidade não são atendidos pois há uma deficiência de área para unidades de dois quartos, comparado à propostas internacionais - Brasil 40m2, Chile $56 \mathrm{~m} 2$ e EUA 96m2; somente em Rodeio os banheiros das unidades não são contíguos à cozinha, e; há um predomínio de sistemas construtivos em madeira, com baixo desempenho térmico.

Por fim, verifica-se que os empreendimentos foram respostas tardias aos desastres hidrológicos ocorridos em 2008, que no caso de Santa Catarina, deixam maior número de pessoas desalojadas. Há necessidade de se considerar o conjunto por meio de Projetos Urbanos e não somente as unidades habitacionais isoladas, dispostas entorno de um sistema viário criado. O planejamento urbano deve prever a ampliação da infraestrutura habitacional nas cidade, buscando áreas com menor vulnerabilidade, priorizando recursos para um crescimento urbano mais ordenado, principalmente para a população sem acesso a lotes urbanos e à habitação. Assim, o investimento na ampliação de equipamentos urbanos, infraestrutura básica, transporte público e habitação pode ser melhor aproveitado. $O$ estudo representou um total de 404 unidades habitacionais construídas no Estado, com desempenho inferior aos requisitos da NBR 15.575. Há necessidade de se rever a forma de provimento das habitações permanentes para a população, oferencendo maior multiplicidade de escolhas, com a possibilidade de se construir unidades habitacionais maiores, com recursos complementados pelo próprio morador, atendendo às diferentes configurações familiares. 


\section{REFERÊNCIAS}

DAVIDSON, C. H; CASSIDY, J; LIZARRALDE, G; DIKMEN, $\mathrm{N}$; SLIWINSKI, A. Truths and myths about community participation in post-disaster housing projects. Habitat International, v. 31, n. 1, p. 100-115. 2007.

DAVIS, lan. Arquitectura de Emergencia. Barcelona, Editorial Gustavo Gilli; 1980. 183p. 